\title{
O (ENTRE) LUGAR DA MULHER: EM CENA JEANNE D'ARPPO
}

\section{THE (BETWEEN) WOMAN'S PLACE: ON THE SCENE JEANNE D'ARPPO}

\author{
Danielle Souza Batista* \\ Nincia Cecília Ribas Borges Teixeira**
}

Resumo: A luta das mulheres para serem reconhecidas como agentes da História vem de longa data. Desde o nascimento, é atribuído à mulher o papel de esposa e mãe. No entanto, a partir da modernidade, surge um novo papel social, adquirido por sua inserção no mercado de trabalho. Isso vai acarretar mudanças na constituição da identidade feminina gerada a partir das novas práticas discursivas. Esse novo papel vai influenciar nas relações sociais, alterando a construção identitária feminina. O corpus do trabalho é a peça teatral Jeanne D’Arppo, escrita por Gardi Hutter em 1981. Jeanne D’Arppo é uma peça teatral cômica, a protagonista apresenta um comportamento característico dos clowns. Uma figura deformada, com aspecto físico desleixado e que traz certa ingenuidade nas ações. Mas, ao mesmo tempo, aproveita-se dessa suposta ingenuidade para criticar e falar indiretamente de questões sociais. Gardi Hutter propõe, por meio do riso, uma reflexão sobre os lugares sociais que a mulher ocupa e quais tarefas lhes são atribuídas. Nesse caso, mais especificamente, trata de um lugar que historicamente é considerado parte do universo feminino: a lavanderia. A pesquisa busca analisar a construção social da identidade da mulher e os agentes fragmentadores dessa nova identidade.

Palavras-chave: Gênero. Representação. Estudos culturais.

\begin{abstract}
The struggle of women to be recognized as agents of history happens long time. From birth the woman is assigned the role of wife and mother. However, from modernity, a new social role, acquired by its insertion in the labor market. This will lead to changes in the constitution of female identity generated from the new discursive practices. This new role will influence social relations bringing major changes in the construction of female identity. The corpus of work is the play Jeanne D'Arppo written by
\end{abstract}

\footnotetext{
" Mestranda em Letras, pela Universidade Estadual do Centro Oeste - Unicentro, Guarapuava, PR. Brasil. Email: dani. sb.88@gmail.com.

** Pós-doutora em Ciência da Literatura, Doutora em letras. Professora Adjunta do Departamento de Letras (UNICENTRO). Vice coordenadora do Programa de Mestrado em Letras da Universidade Estadual do Centro Oeste - Unicentro, Guarapuava, PR. Brasil. E-mail: ninciaborgesteixeira@yahoo.com.br
} 
Gardi Hutter in 1981. Jeanne D'Arppo is a comic play, the protagonist has a characteristic behavior of the clowns. A deformed figure with unkempt physical appearance and that brings certain naivety in the actions. But at the same time takes advantage of this supposed naivete to criticize and speak indirectly to social issues. Gardi Hutter proposes, through laughter, a reflection on the social places that women occupy and which tasks they are assigned. In this case, more specifically, is a place that is historically considered part of the feminine universe: the laundry. The research analyzes the social construction of women's identity and fragmentary agents of this new identity.

Keywords: Gender. Representation. Cultural studies.

1. BASTIDORES

As lutas de representações, conforme Roger Chartier (1988), apontam para conflitos e mecanismos de poder utilizados para estabelecer grupos e suas visões de mundo sobre outros: "As lutas de representações têm tanta importância como as lutas econômicas para compreender os mecanismos pelos quais um grupo impõe, ou tenta impor, a sua concepção do mundo social, os valores que são os seus, o seu domínio" (CHARTIER, 1988, p.17). A construção do masculino e feminino determinou os lugares, ações e papéis que cabiam a cada sexo. $O$ estudo de gênero não tenta compreender os modelos e as identidades fixadas socialmente na essência do feminino ou do masculino, de forma naturalizada e a-histórica, mas nas relações entre homens e mulheres de um dado momento e de um dado local. As abordagens de gênero "[...] procuram, assim recobrar o pulsar na história, recuperar sua ambiguidade e a pluralidade de possíveis vivências e interpretações, desfiar a teia de relações cotidianas e suas diferentes dimensões de experiência, fugindo dos dualismos e polaridades e questionando as dicotomias" (MATOS, 1997, p.80).
A atuação da mulher, nos variados contextos sociais, foi construída por lutas, palavras e também silêncio. Silêncio que gerou sentidos e mudou o curso da História. Nesse universo em transformação, inúmeros foram os discursos que socialmente se elucidaram a respeito da questão de gênero e diferentes foram os sentidos a ele atribuídos. A sociedade patriarcal traduz bem esse silêncio que denuncia as formas de opressão a que foram submetidas às mulheres. Ao longo da história, mulheres de variadas culturas, assumiram papéis que estiverem numa posição, quase sempre inferior às funções assumidas por homens. Em algumas sociedades, as mulheres foram, e ainda são, vítimas de abuso de poder. O único lugar em que a mulher pôde ter a falsa sensação de estar no comando foi dentro de sua própria casa.

Para Borges-Teixeira (2012), a emergência do movimento feminista, no final da década 1960, produziu novos modos de representação do feminino no campo da arte, desencadeando, assim, a necessidade de questionamentos sobre a formação da identidade de gêneros e suas respectivas "funções" dentro da sociedade ocidental. No âmbito artístico, o gênero loca-se no processo de questionamento da grande presença 
de nomes masculinos na História da Arte, no mercado de arte, e na inserção midiática das recentes temáticas contemporâneas, ou seja, as poéticas intimistas, sexuais e subjetivas.

A questão do gênero e, posteriormente, o feminismo, criaram, assim, pontes de diálogo com o universo feminino dentro do universo artístico, até então estritamente masculino. Durante grande parte da história da arte ocidental, as mulheres figuravam como musas ou assistentes e não como artistas criadoras. Deixando de serem espectadoras, as mulheres tomaram a "liberdade" de serem criadoras, e de determinarem suas imagens artísticas, de elegerem suas poéticas. O movimento feminista na arte vem então para desconstruir a premissa de mulher objeto de desejo. De musas inspiradoras para o olhar do artista, a mulher passa a ser o olho e a mão que cria.

Ao tentar romper com essa perspectiva histórica, muitas escritoras, jornalistas, artistas e compositoras explicitaram em seus trabalhos a insatisfação com tal condição. Gardi Hutter foi uma dessas mulheres, autodirigiu-se e produziu quatro solos clownescos. A pesquisa analisa a peça Jeanne D’Arppo, criada em 1981 por Hutter.

\section{ENSAIOS}

O ser humano é essencialmente um ser de linguagem, em nenhum outro momento de sua história, porém, o homem se viu emaranhado em uma pluralidade tão extraordinária de linguagens quanto na atualidade. As ciências, as artes, a psicanálise e os meios de comunicação - detentores de códigos particulares - transformaram o mundo em uma grande massa de signos.
Essa abundância de linguagens acabou por forçar uma diluição de suas fronteiras, mas jamais a demarcação desses territórios foi tão imperceptível e irrelevante quanto hoje, quando, por exemplo, buscamos estabelecer o relacionamento entre duas formas de manifestações artísticas.

Apesar da migração de signos e recursos de um campo para outro se constituir em um fenômeno que atingiu todo o campo das artes - literatura, teatro, dança, música, pintura - jamais se registrou como agora com tanta frequência e intensidade esse fenômeno. Por outro lado, não se pode negar que o surgimento dos meios de comunicação trouxe em seus rastros profundas transformações, ampliando significativamente nossas potencialidades sensitivas e reconfigurando nossos campos perceptivos. Esse entrelaçamento dos signos e a inserção desses no panorama social afetaram, inclusive, o domínio das artes, ao promover significativas alterações nas formas de sentir, pensar, ver e apreender o mundo, enfim, de traduzi-lo em palavras e imagens.

A literatura é reflexo das relações sociais, desta forma, é comum encontrar em obras literárias perfis de mulheres estereotipadas de acordo com os modelos civilizadores, ocidentais. No estudo de gênero, a análise da representação torna-se fundamental para se pensar no texto literário e no conceito com o contexto em que este é produzido. Sendo assim, o conceito de representação está ligado ao poder, uma vez que os discursos dominantes no meio social estão ligados ao poder.

Apesar das campanhas de emancipação da mulher iniciadas nas décadas 1960 e 1970, nota-se uma fraca participação desta na produção literária. Na medida em que as mulheres vão saindo desse encarceramento e 
assumindo sua atividade de empoderamento como sujeitos, a interferência no cânone literário também se realiza. Essa mulher, que agora inscreve seu discurso, irá se apropriar desses estereótipos, mas com certeza o fará de um modo a subverter esse poder de silenciar e construir falseamentos. É o que percebemos no discurso de Gardi Hutter.

Gardi Hutter não é uma escritora qualquer. É palhaço. É uma das mais famosas palhaças do mundo. Nasceu na Suíça, em 1953, estudou interpretação, juntou-se a uma companhia. Para ela, ser palhaço é complicado, porque há muitos estigmas, então para as mulheres é mais complicado ainda. Foi um caminho que ela precisou percorrer sozinha. Para ela:

[...] no teatro não tem papel para mulher cômica, nem no teatro clássico, nem no teatro moderno. Então, durante minha formação na escola, trabalhei como atriz durante um ano no teatro e na televisão, mas era muito chato, muito cansativo porque não tinha nenhum papel que fosse realmente interessante para mim. Normalmente os papéis que se ofereciam pras mulheres nos teatros eram de personagens muitos doentes ou muito tristes. (HUTTER, 2011).

Jeanne D'Arppo é uma peça teatral cômica, a personagem principal apresenta um comportamento característico dos clowns. Uma figura deformada, com aspecto físico desleixado e que traz certa ingenuidade nas ações, mas, ao mesmo tempo, aproveita-se dessa suposta ingenuidade para criticar e falar indiretamente de questões sociais, mostrando-as de outro ponto de vista. Ana Elvira Wuo afirma que o ator cômico tem "[...] como objetivo inverter a ordem pré-estabelecida, construindo uma capacidade de parodiar e de rir das situações humanas" (WUO, 2008 p. 57).

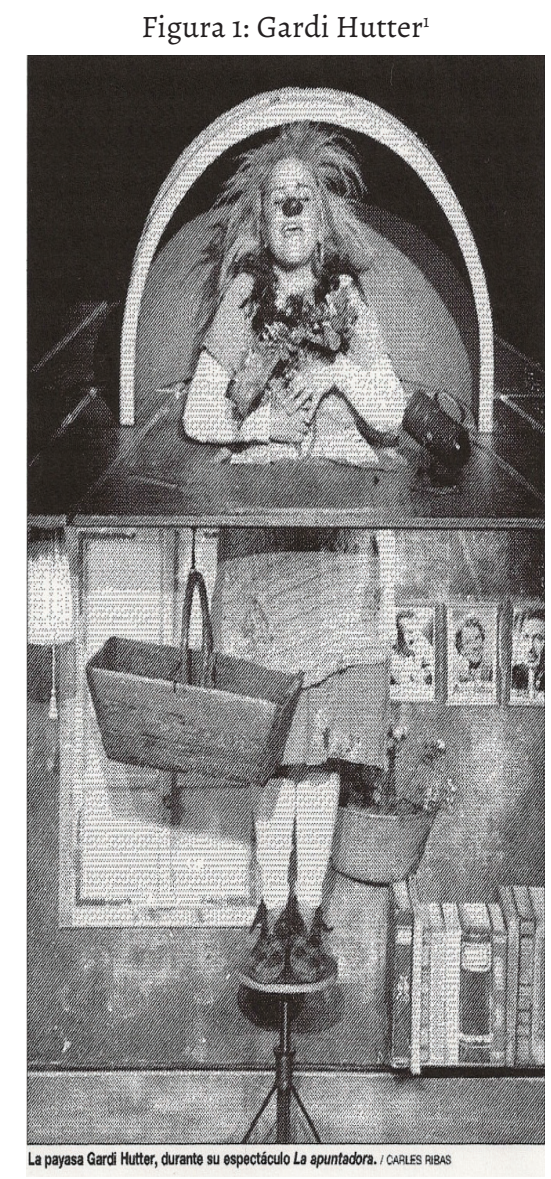

A pesquisa contribui para a visibilidade dos trabalhos de autoria feminina dentro das artes cênicas, e por discutir questões altamente debatidas por teóricas feministas. As observações de Elza Cunha de Vincenzo corroboram com essa ideia:

1 Disponível em: http://www.gardihutter.com/website/ images/stories/PDF/20070604_ElPais.pdf 
A riqueza e a variedade dos temas abordados, a qualidade de sua elaboração em termos tanto conteudísticos quanto formais, de modo geral, indicam a realização de um aspecto de uma das mais importantes metas do feminismo mundial e brasileiro deste século: a abertura e o alargamento de espaços para a manifestação e a atuação da mulher em órbitas do não privado, do não exclusivamente doméstico. (VINCENZO, 1992: 277).

\section{EM CENA: JEANNE D’ARPPO}

O feminino não está apenas na mulher, muito menos o masculino sempre no homem. Todo ser humano comporta os dois aspectos, as duas qualidades, as duas forças, concentrando em si mesmo a capacidade de tornar-se equilibrado. É necessário salientar esse ponto para evitar a queda num simplismo de gênero do tipo: feminino está para mulher assim como masculino está para o homem. Tradicionalmente, a atribuição é essa. No entanto, com o desenvolvimento das sociedades e de novos processos de experimentação das relações humanas seria inapropriada uma divisão tão estanque e empobrecedora das "forças" masculinas e femininas.

Gardi Hutter, na peça Jeanne D’Arppo, propõe pelo riso uma reflexão acerca do lugar da mulher na sociedade, nesse caso, mais especificamente, trata de um lugar que historicamente é considerado parte do universo feminino: a lavanderia. De acordo com Eric Sales (2011), o humor, o risível e os diversos personagens cômicos possuem características diretamente ligadas ao espírito crítico das sociedades humanas, que reagem sempre às injustiças sociais. Assim, diversos foram os meios que os indivíduos utilizaram e utilizam para se expressar, constituindo tais meios em importantes instrumentos de interpretação da sociedade.

Alguns espaços são considerados especificamente femininos ou masculinos, Teresa de Lauretis utiliza para isso o termo "espaços gendrados" (LAURETIS, 1987), para se referir a espaços que são marcados por especificidades de gênero.

Segundo Lauretis, não se pode classificar uma pessoa num espaço do feminino e do masculino, levando em consideração apenas o sexo com o qual nasceu. Se assim o fizermos, estaremos reforçando ainda mais o que a pesquisadora chama de (en)gendramento. Espaços gendrados poderiam ser exemplificados ou simplificados como espaço de homem e espaço de mulher. Como se existisse um território específico para cada sexo, e não fosse natural a transição entre eles. Essa falta de naturalidade na transição se dá justamente pela construção social daquele sujeito.

O espaço da lavanderia como elemento essencial da obra e o ato de lavar, foco da peça, tornam-se a síntese de todo trabalho doméstico forçado ao qual a mulher é compelida. No século XIX, cuidar das roupas de casa era uma tarefa difícil nas cidades, pois a falta de espaço não permitia o bom trato com as peças. Assim, as lavadeiras especializadas se multiplicaram. Era uma maneira de completar o tempo das donas de casa. Michele Perrot afirma serem três as categorias a que pertencem as mulheres que frequentavam os lavadouros:

[...] as lavadeiras profissionais que lavam para as burguesas, as donas-de-casa que 
lavam suas próprias roupas, e uma categoria intermediária, as por peça, que lavam para si e tiram alguns trocados lavando algumas peças para uma comerciante ou vizinha. (PERROT, 1988 p.227).

A criação desses espaços tinha outros objetivos, além da preocupação com a urbanização; queria limitar o comportamento da mulher e seu relacionamento com outras pessoas, "[...] para que cada lavadeira pudesse lavar sua roupa sem tagarelar com a vizinha" (PERROT, 1988, p.226). Percebendo isso, as donas-de-casa boicotaram o lavadouro do Templo. Além de um local de encontro das mulheres, o lavadouro também era uma oportunidade de distração. Durante o período de trabalho, por lá passavam vendedores ambulantes, o "tirador de fotografia” (PERROT, p.228), cartomantes e cantores. Muitas oportunidades de aprender coisas que não seriam necessárias para uma mulher de costumes.

Tentando não perder o controle, o lavadouro passa a ser uma tentativa de disciplinar mulheres rebeldes. Educação da limpeza e da ordem. Há uma intervenção política, controle da distribuição da água e da organização na estrutura do lavadouro. Existia a figura de um mestre de lavagem, que controlava qualquer excesso e tinha um papel de instrutor e disciplinador. Porém "como essas mulheres não deixavam de revidar, o mestre de lavagem com certa frequência era colocado em seu devido lugar". (PERROT, p. 230). A mulher, dentro dos lavadouros, tinha voz.

O cenário da peça apresenta um ambiente doméstico. Um tanque e uma pilha imensa de roupas para lavar e um varal são os elementos principais na composição desse ambiente. A personagem aparece vestida com uma roupa remendada e que é finalizada por um avental bem tradicional. Seus cabelos são descuidados, secos e arrepiados e no rosto um grande nariz vermelho traz a referência do clown. A aparência da personagem não é em vão, visto que a imagem com que essa mulher se apresenta demonstra o desgaste pelo trabalho doméstico.

Logo no início da peça a personagem aparece com um livro amarelo debaixo do braço, que conta a história de Joana D’arc. A personagem, então, se depara com o tanque, com a montanha de roupas e nada faz para mudar aquele cenário. Disfarça, brinca e cria situações para tirar o foco da atividade que tem que realizar. O livro amarelo é mais interessante do que qualquer outra coisa naquela lavanderia. A personagem lê e encena trechos do que parece ser uma batalha. Ela parece realmente admirada ou surpresa com as histórias que lê. O monte de roupas toma diversas formas: uma ilha, um cavalo e um trono real. Jeanne tem uma atitude definida como masculina quando extrapola as lides domésticas, ou seja, de aventureira, que segue livre pelo espaço público.

A História é um discurso soletrado no masculino, apenas reconhece a presença das mulheres nos lugares autorizados, isto é, no espaço privado da domesticidade e não no da política, da economia e da guerra. E isso não se dá por acaso, pois, afinal, o privado é o lugar do confinamento, da exclusão do mundo público e da cidadania. Ou, como bem define Hannah Arendt (1995), é o lugar da "privação", da "ausência" ou do sentimento de não existir. 
Em determinado momento, surge um monstro feito de dezenas de roupas sujas, e o tormento que esse monstro se torna na vida da personagem. Temos em cena não apenas um aglomerado de roupas a serem lavadas, mas uma parte do cenário que é signo de excesso de trabalho, talvez até de desleixo, devido à quantidade de roupas acumuladas. O mostro passa a ser, portanto, metáfora do trabalho doméstico a que ela se recusa a se submeter, o inimigo a ser vencido. Jeanne D'Arppo resolve vencer o monstro, não se deixar devorar. Para isso, reveste-se de sua heroína Joana D’arc., para vencer a guerra contra a opressão masculina, que trava contra si mesma, contra a sociedade que lhe coloca como um sujeito que só tem voz dentro de um espaço privado.

Todos esses fatos influenciaram a trajetória da personagem no enredo da peça. Essa mulher quer mais do que ser sujeitada a realizar um trabalho que lhe faz apenas uma boa dona de casa. Quer lutar, como Joana D'arc., quer fazer mais do que a sociedade lhe permite ou lhe permitiu. As atitudes da personagem nos remetem aos estudos feministas, pois "[...] o feminismo [...] caracteriza-se por uma intensa preocupação em criar novos espaços sociais e outras condições subjetivas para as mulheres, na luta contra os modelos de feminilidade impostos pela dominação classista e sexista" (RAGO, 2008 p.166).

A partir da identidade de Joana D'Arc, ela inicia um processo de negação do sujeito feminino historicamente construído. As negações às práticas de subjetivação acontecem em dois momentos da peça mais explicitamente: quando do uso da calça e da negação da maternidade. É aqui que a ligação com as questões de gênero ficam mais evidentes, pois são temas bastante citados, principalmente por autoras feministas.

[...] as feministas lutaram para alterar as condições de formação e educação das meninas e moças, incitando-as a que procurassem construir-se automaticamente, rejeitando as sujeições cotidianamente impostas pelo sistema patriarcal e experimentadas na própria carne. Críticas da definição biológica da mulher como estreitamente vinculada ao útero, da maternidade obrigatória e da mistificação da esfera privada do lar, elas têm lutado para que outras formas de invenção de si se tornem possíveis para as próprias mulheres. (RAGO, 2008 p.166).

O uso da calça esbarra diretamente com a questão colocada por Rago (2008), sobre a educação das meninas e moças. A partir do momento em que a personagem coloca a calça, muda visivelmente a maneira de se comportar. Seu andar é mais solto, ela ousa abrir as pernas e acha graça disso. Joana D'arc conseguiu o respeito dos soldados parecendo ao máximo com eles: de calças, cabelos curtos e armadura.

A segunda ação que mostra a negação das práticas de subjetivação é a negação da maternidade. A personagem ensaia suas lutas, como deve se comportar e como usar a espada, sempre inspirada em Joana D’arc. Até que, em certo momento, ela se dá conta que todas aquelas ações não combinam com o dia a dia de uma mãe de família. Por meio de gestos, ela mostra que não poderá lutar e ao mesmo tempo de preocupar com o choro de uma criança, que a armadura não lhe 
permitirá amamentar e, então, o que ela faria com aqueles seios? Para ela, nesse novo papel que assumiu, eles não fazem nenhum sentido, tanto que ela até sugere retirá-los, mudá-los de lugar e transformá-los em músculos.

Depois de muitas tentativas e buscas por informações no livro, a personagem consegue acertar o monstro com sua espada e arrancar-lhe a cabeça. Alegorizando a conquista das mulheres ao direito de transitarem pelo espaço público, inclusive o de escrever e ter lugar de fala no espaço da cultura, definido como de domínio masculino. Vencendo, assim, a batalha e tendo como consequência a reformulação do espaço público.

A peça acaba com a morte da personagem, que segundos depois ressurge como um anjo, com asas e uma auréola sobre a cabeça. Morte simbólica que marca o fim de um estado: a submissão; e o (re)nascimento de outro: a liberdade de escolha. Assim, Jeanne, de acordo com Margareth Rago "promove novos modos de constituição de si, subvertendo os códigos burgueses de definição das mulheres, como esposas, mães, figuras exclusivas do lar [...]" (2008 p.169).

\section{AbaiXam-Se AS CORTinas}

As representações se constituem em categorias importantes na medida em que, por seu intermédio, vislumbra-se a natureza das formações discursivas em que foram concebidas, as relações de poder, os elementos da dominação e da resistência. Ao se representar está-se concomitantemente estabelecendo identidades e relações. Essa dimensão da representação torna-se ainda mais evidente quando se lida com produção literária e seu poder de influenciar as crenças, os valores, as identidades e a memória social.

Ao representar a figura feminina, constrói-se, projeta-se e estabiliza-se a identidade social, em processos definidos histórica e culturalmente. As práticas sociais de representação vigentes de uma certa época se cristalizam em formas textuais. É possível associar as representações às ordens de discurso a que estão genealogicamente relacionadas e, também, a outros discursos que circulam na sociedade. As práticas discursivas, além de sua dimensão constitutiva na construção social da realidade, constituem também ação social.

A peça de Gardi Hutter apresenta a transformação da condição de subjugada da mulher. $O$ texto rompe com os discursos sacralizados pela tradição, nos quais a mulher ocupa, à sua revelia, um lugar secundário em relação ao lugar ocupado pelo homem. Tais discursos não só interferem no cotidiano feminino, mas também acabam por fundamentar os cânones críticos e teóricos tradicionais e masculinos que regem o saber sobre a literatura.

Em Jeanne D'Arppo ocorre a desconstrução da oposição homem/mulher, entendida no mesmo sentido que a relação dominador/dominada, numa espécie de versão do pós-estruturalismo. Mulher frágil, dependente, obediente, submissa, mãe, dona de casa; esses são papéis que Jeanne D'Arppo se recusa a assumir. $\mathrm{Na}$ peça, observa-se a negação desses rótulos. A identificação com Joana $D^{\prime}$ arc a faz mais corajosa, com tendência a arriscar mais e sem medo do que os outros irão pensar.

A poética desenvolvida pela atriz e escritora Gardi Hutter é uma espécie de labirinto em que se perdem e se encontram os reflexos sociais entre os quais circulam e 
se configuram a personagem, o leitor e a própria autora; ocorre, de certa forma, a negação da identidade pré-construída. Segundo Rajagopalan (2002), é por meio da representação que se afirmam e reivindicam com frequência novas identidades. Produzir textos representa produzir propostas de significação com efeitos de sentidos que não são permanentes ou estáveis, pois o sentido se efetiva no ato do processamento pelo seu leitor/ouvinte, que pode fazer parte de contextos socioculturais diversos. Isso significa que toda nossa capacidade de lidar com o mundo e de ligar conhecimentos provém de nossos interesses e de nossa habilidade de organizar a experiência cognitivamente.

\section{REFERÊNCIAS}

ARENDT, H. A condição humana. Rio de Janeiro: Forense Universitária, 1995.

AQUINO, E. D. Catolicismo popular através da representação mística/mítica de Joana $D^{\prime}$ arc. In: ENCONTRO ESTADUAL DE HISTÓRIA, 13, 2008, Guarabira/Paraíba. Anais... Guarabira/ Paraíba: UFPB/UEPB/UFCG, p.01-08, 2008. Disponível em: <http://www.anpuhpb.org/ anais_xiii_eeph/autores.html>.

BORGES-TEIXEIRA, N. C. R. Gênero, silenciamento e opressão: interfaces entre imagens e letras. Terra roxa e outras terras - Revista de Estudos Literários, v. 24, p.1-150, dez. 2012. CURCIO, L. Entrevista Gardi Hutter. Disponível em: <http://conexaopalhaca.blogspot.com.br/2013/ 03/a-palhaca-da-semana-gardi-hunter.html>.

CHARTIER, R. A história cultural: entre práticas e representações. Rio de Janeiro: Bertrand, 1998, p. 17.
LAURETIS, T. de. A tecnologia do gênero. In: Technologies of gender. Indiana University Press, 1987.

MAGALDI, S. Iniciação ao teatro. São Paulo: Editora Ática, 1991.

PERROT, M. Os excluídos da história: operários, mulheres e prisioneiros. Rio de Janeiro: Paz e Terra, 1988.

RAGO, M. Figuras de Foucault. Belo Horizonte: Autêntica, 2008.

VINCENZO, E. C. de. Um teatro da mulher: dramaturgia feminina no palco brasileiro contemporâneo. São Paulo: Perspectiva: Editora da Universidade de São Paulo, 1992. WUO, A. E. A linguagem secreta do clown. Integração. São Paulo, ano 15, n. 56, jan/fev/ mar, 2009, p.57-62.

MATOS, M. I. S. de. Gênero e história: percursos e possibilidades. In: SCHPUN, M. R. (Org.) Gênero sem fronteiras: oito olhares sobre mulheres e relações de gênero. Florianópolis: Editora Mulheres, 1997, p.80.

RAJAGOPALAN, K. A construção de identidades e a política de representação. In: FERREIRA, L. M. A.; ORRICO, E. G. D. (Orgs.). Linguagem, identidade e memória social: novas fronteiras, novas articulações. Rio de Janeiro: DP\&A, 2002.

SALES, E. O riso como crítica: indícios para serialização e análise da filmografia dos Trapalhões. Anais do XXVI Simpósio Nacional de História - ANPUH. São Paulo, julho 2011. Disponível em: <http://www.snh2011.anpuh.org/site/ anaiscomplementares\#S $>$.

Recebido para publicação 29 abr. 2013 Aceito para publicação 30 jul. 2013 